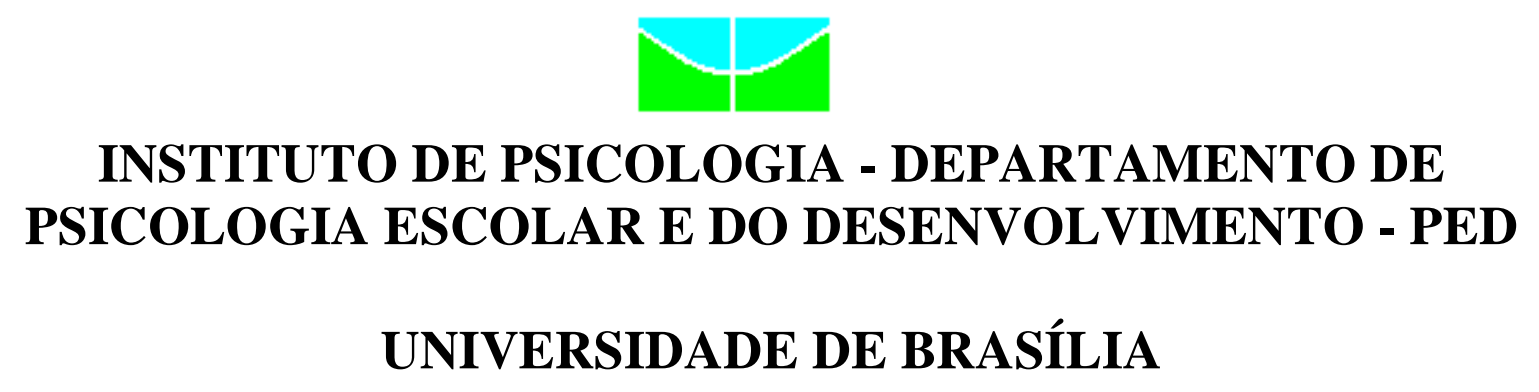

CURSO DE ESPECIALIZAÇÃO EM PSICOPEDAGOGIA CLÍNICA E INSTITUCIONAL

TURMA IX

(2010/2011)

Coordenação: Profa. Dra. Maria Helena Fávero

TRABALHO FINAL DE CURSO:

A CONSIDERAÇÃO ENTRE COMPETÊNCIAS E DIFICULDADES NA PRÁTICA PSICOPEDAGÓGICA

Apresentado por: Ivianie Pinheiro Magalhães Porto

Orientado por: Dra. Maria Helena Fávero

BRASÍLIA, 2011 


\section{A CONSIDERAÇÃO ENTRE COMPETÊNCIAS E DIFICULDADES NA PRÁTICA PSICOPEDAGÓGICA}

Apresentado por: Ivianie Pinheiro Magalhães Porto

Orientado por: Maria Helena Fávero 


\section{ÍNDICE}

I/ Colocação do Problema..................................... 03

II/ Fundamentação Teórica..................................... 03

III/ Método de Intervenção

3.1 Sujeito........................................ 10

3.2 Procedimento Adotado.................................. $10 \quad 10$

IV/ A intervenção psicopedagógica: da avaliação psicopedagógica à discussão de cada sessão de intervenção

4.1/ Avaliação psicopedagógica........................... 11

- sessão de avaliação psicopedagógica $1 \ldots \ldots \ldots \ldots \ldots \ldots \ldots \ldots \ldots . \ldots \ldots$

- sessão de avaliação psicopedagógica $2 \ldots \ldots \ldots \ldots \ldots \ldots \ldots \ldots \ldots . \ldots . \ldots . \ldots 13$

- sessão de avaliação psicopedagógica $3 \ldots \ldots \ldots \ldots \ldots \ldots \ldots \ldots . \ldots . \ldots . \ldots 14$

- sessão de avaliação psicopedagógica $4 \ldots \ldots \ldots \ldots \ldots \ldots \ldots \ldots \ldots . \ldots . \ldots . \ldots 15$

- sessão de avaliação psicopedagógica $5 \ldots \ldots \ldots \ldots \ldots \ldots \ldots \ldots \ldots . . \ldots 17$

4.1.1 Discussão Geral da avaliação psicopedagógica ....... 19

4.2/ As Sessões de Intervenção

- sessão de intervenção psicopedagógica $1 \ldots \ldots \ldots \ldots \ldots \ldots \ldots \ldots . \ldots 21$

- sessão de intervenção psicopedagógica $2 \ldots \ldots \ldots \ldots \ldots \ldots \ldots . \ldots 23$

- sessão de intervenção psicopedagógica $3 \ldots \ldots \ldots \ldots \ldots \ldots \ldots . \ldots 24$

- sessão de intervenção psicopedagógica $4 \ldots \ldots \ldots \ldots \ldots \ldots \ldots . \ldots . \ldots 26$

- sessão de intervenção psicopedagógica $5 \ldots \ldots \ldots \ldots \ldots \ldots \ldots . \ldots 28$

- sessão de intervenção psicopedagógica $6 \ldots \ldots \ldots \ldots \ldots \ldots \ldots . \ldots . \ldots 29$

V/ Discussão geral dos resultados da intervenção psicopedagógica......................................... 30

VI/ Considerações Finais..................................... 34

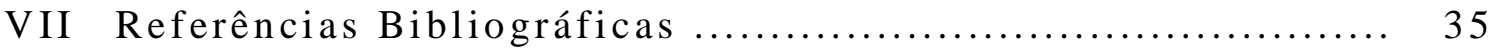




\section{I/ Colocação do Problema}

O foco deste trabalho é a relação entre a psicologia do conhecimento e a prática psicopedagógica na defesa de uma intervenção que beneficie a verdadeira articulação entre competências e dificuldades.

Sua fundamentação, como apresentamos a seguir, baseia-se Teberosky (1990), Fávero (2005), Oliveira e Bossa (2008), Barrera e Maluf(2003), Colomer e Camps (2002), A. G.S.Capovilla \& F.C. Capovilla (2004) e outros.

Esse trabalho está estruturado em três partes. Na primeira fundamentamos a sua questão central como anunciado no primeiro parágrafo. Nela defendemos que as dificuldades de aprendizagem devem ser mediadas através de uma articulação entre competências e dificuldades, e isso, em particular, nesse trabalho, com relação à construção das competências relacionadas a leitura, escrita e matemática.

$\mathrm{Na}$ segunda parte, descrevemos uma prática psicopedagógica desenvolvida com uma criança na faixa etária de 7 anos.

Finalmente, na última parte, a título de conclusões, desenvolvemos algumas considerações finais, retomando nosso foco, ou seja, a relação entre a psicologia do desenvolvimento infantil e a prática psicopedagógica focada na articulação entre competências e dificuldades.

\section{II/ Fundamentação Teórica}

Um dos desafios atuais do sistema de ensino é lidar com alunos que apresentam dificuldade de aprendizagem. Sabemos que vários fatores podem justificar tal fato. Esses fatores podem ser internos ou 
externos. Coerente com o exposto antes, nosso trabalho visou a avaliação das competências e dificuldades da criança e a posterior prática psicopedagógica baseada nessa articulação.

A Psicopedagogia é a área do conhecimento que busca compreender o processo de aprendizagem, buscando, assim, relacionar diversas áreas do conhecimento na investigação do complexo fenômeno da aprendizagem. Oliveira e Bossa (2008) afirmam que a psicopedagogia têm construído sua teoria a partir do estudo dos problemas de aprendizagem.

De acordo com Oliveira e Bossa (2008), a preocupação com os problemas de aprendizagem datam do século XVII. Infelizmente, ainda hoje observamos reflexos do modo como tais problemas eram encarados antigamente.

Abordando essa questão de um modo mais amplo, Fávero (2005) afirma que a maneira como nos relacionamos com o conhecimento científico influencia nossa prática pedagógica já que isso é mediado por nossa sóciocultura. Uma visão clássica da ciência, positivista, onde a subjetividade na construção do conhecimento cientifico é negada acaba por influenciar as práticas psicopedagógicas. Nessa perspectiva a avaliação psicopedagógica tende a ser reduzida a um instrumento medidor de faltas ou déficits, o que reduz as intervenções a um plano para suprir tais deficiências. A tendência na instituição escolar é criar um ambiente extremamente tradicional, de educação depositória, onde o conhecimento é "passado" de maneira passiva e inquestionável.

$\mathrm{Na}$ perspectiva de Cunha e Fávero (2009), a tendência positivista em que a memorização de regras tem maior valor do que a compreensão conceitual, dificulta o desenvolvimento das competências e do pensamento crítico em relação ao próprio conhecimento. 
$\mathrm{Na}$ proposta de Fávero (2005) fica evidente a importância da Psicologia para a prática pedagógica e psicopedagógica, na medida em que a autora articula o desenvolvimento humano e o desenvolvimento do conhecimento, em uma perspectiva que visa a articulação entre conhecimento, indivíduo e sociedade.

Sabemos que a ciência não é neutra, pois surge de contextos sociais e históricos específicos. Portanto, durante a atividade interventiva devemos tomar consciência das nossas práticas enquanto educadores e conduzir o sujeito a tomar consciência do seu processo de aprendizagem.

Podemos dizer que as duas competências mais exigidas para o sucesso na escola são a capacidade de leitura e escrita e as noções de aritmética, incluindo as 4 operações básicas.

De modo particular, a capacidade de fazer bom uso da língua escrita é uma das exigências do estudo formal que irá gerar diversas expectativas na vida das crianças que estão na escola, sobretudo por parte dos próprios professores. Um dos riscos é que essa criança fique marginalizada na sala de aula. Nesse contexto constitui-se um círculo vicioso onde a criança acredita-se que a criança não é capaz, e por tal motivo é afastada e pela realidade escolar como parâmetro para o bom desempenho. Ou seja, não se considera o desenvolvimento de cada criança em relação a si mesma.

Influenciadas por Piaget, Teberosky e Ferreiro (1986) acreditam que para chegar a um novo conhecimento a criança precisa passar por algumas etapas. Existe uma continuidade na construção do conhecimento onde a transformação cognitiva acontece devido a esquemas que se acomodam aos pré-existentes e da assimilação de novos conhecimentos.

Assim, desde cedo, a criança elabora ideias sobre os sinais gráficos que acompanham os objetos. A escrita não é adquirida 
somente na escola, surge da necessidade de nos comunicarmos e compreender a linguagem não verbal (Teberosky e Ferreiro, 1986).

Elas formularam quatros estágios de desenvolvimento da aquisição escrita, quais sejam:

- pré-silábico: onde a criança não compreende que existe uma relação entre o registro gráfico e a fala;

- silábica: a criança começa a perceber que o que ela escuta tem relação com o que se escreve.

- silábico-alfabético: ele começa a perceber o principio alfabético da língua.

- alfabético: cada letra corresponde a menor unidade da escrita.

A leitura pode ser compreendida apenas como um ato de entender um texto. Porém, estudos revelam que se trata de uma atividade muito complexa relacionada, inclusive, com a compreensão que o indivíduo faz do mundo e da maneira como ele se relaciona com os demais conhecimentos que irá adquirir ao longo a vida.

Dentro da aprendizagem formal, a aquisição da leitura é uma importante conquista para que ocorra a aprendizagem em todas as demais áreas do conhecimento. A capacidade de se comunicar com o outro é essencial para a construção do conhecimento. E essa habilidade surge ainda nos primeiros contatos que o ser humano faz com o mundo, antes mesmo da fala. A aptidão de se comunicar vai se aprimorando, ao passo que a leitura e a escrita surgem como uma nova e importante etapa da comunicação do ser humano.

A capacidade metalinguística é essencial para a aquisição da escrita. Barrera e Maluf (2003) acreditam que

nos últimos 20 anos, os autores parecem concordar que a aprendizagem da leitura e escrita em sistemas alfabéticos pressupõe uma reflexão deliberada da fala que, utilizada de forma natural e eficiente pela criança nas situações 
comunicativas do dia a dia, deve tornar-se objeto de sua atenção consciente, a fim de permitir o desenvolvimento do que se costuma designar como conhecimento ou consciência metalinguística. A consciência metalinguística é um termo genérico que envolve diferentes tipos de habilidades, tais como: segmentar e manipular a fala em suas diversas unidades (palavras, sílabas, fonemas); separar as palavras de seus referentes (ou seja, estabelecer diferenças entre significados e significantes); perceber semelhanças sonoras entre palavras; julgar a coerência semântica e sintática de enunciados. ( p. 491 e 492)

Nos estudos de Martins (1994) o conceito de leitura muitas vezes está associado apenas a decifração da escrita e contraargumenta citando Paulo Freire, para quem "a leitura do mundo precede a leitura da palavra a leitura desta implica na continuidade da leitura daquele" (citado por Martins, 1994).

Martins (1994) "Ler significa inteirar-se do mundo sendo também uma forma de conquistar autonomia deixar de ler pelos olhos de outrem" (p. 23).

Os estudos de Colomer e Camps (2002) encontraram que

a possibilidade de utilizar a língua escrita tem consequências profundas nos processo mentais dos indivíduos e das sociedades alfabetizadas, consequências em sua forma de simbolizar a realidade, de estruturar seu conhecimento do mundo e de conceber novas formas de adquiri-lo.(p. 22)

O texto escrito nos ajuda na apropriação do conhecimento humano, pois facilita a percepção e a compreensão de realidades de outras pessoas e confronta-las com as nossas, com o intuito de integra-las com o nosso conhecimento.

Capovilla e Capovilla (2004) argumentam que a análise das dificuldades de leitura e escrita auxiliam na compreensão desses 
processos. Eles acreditam que a busca por modelos teóricos que explicam quais são as competências, imprescindíveis para que a leitura e escrita se desenvolvam, guiarão as intervenções no campo da lecto-escrita.

Pesquisas no campo da lecto-escrita formularam várias hipóteses que persistiram por vários anos como explicação das dificuldades de leitura e escrita. As primeiras eram baseadas na Hipótese de Déficit Visual. Durante 50 anos acreditou-se que problemas de leitura e escrita estavam associados às dificuldades de processamento de padrões visuais, segundo Capovilla e Capovilla (2000) citado por Capovilla e Capovilla (2004). Tais estudos davam ênfase ao estudo da percepção, discriminação e organização visual.

Novos estudos começaram a combater essa hipótese e surgiu a Hipótese do Déficit Fonológico. Pesquisas começaram a considerar que as dificuldades com o processamento visual tinham relação com as dificuldades de leitura e escrita, mas não poderiam ser tidas como sua causa de acordo com Capovilla e Capovilla (2000) citado por Capovilla e Capovilla (2004). Sendo assim, as dificuldades fonológicas passaram a predizer as dificuldades em leitura e escrita. Estudos apontam que dificuldades fonológicas e metafonológicas (segmentação e manipulação intencionais de segmentos da fala) são adequadas de prever dificuldades na aprendizagem de leitura e escrita.

\section{Aprendizagem de matemática}

O conceito de numeralização é muito importante para a aprendizagem da matemática. Tal termo é defendido nos estudos de Nunes e Bryant (1997) onde a numeralização denomina uma criança ou adulto que tenha domínio do sistema numérico e das operações 
aritméticas, com competência de pensar com o conhecimento matemático.

Para esses autores a criança precisa ser lógica para ser numeralizada e defendem que a lógica se aplica a diversas matérias escolares, porém a relação entre a matemática e a lógica é forte e clara. Para elas as tarefas matemáticas básicas podem ser desenvolvidas apenas por alguém que reconheça as regras lógicas.

Assim, o sistema numérico decimal fundamenta-se em uma lógica que por sua vez fundamenta o algorítmico das 4 operações formais e o próprio conceito de número.

O conceito de número requer a noção de conservação: entender que um conjunto de objetos só pode ser alterado por adição ou subtração de novos componentes. Da mesma forma, tal conceito requer também a ideia de que se A é maior que um número $B$ e o número C é menor que B, logo A é maior que C.

Do ponto de vista da aprendizagem, Nogueira (2011) defende que a contagem desempenha um papel importante no conceito de número. Defende que não apenas as atividades lógicas, mas, também, as numéricas devem ser consideradas na prática escolar.

Portanto, considerar a intervenção psicopedagógica com crianças que apresentem dificuldades com as operações básicas da matemática escolar, significa considerar: 1. As relações entre suas competências e dificuldades; 2 . Desenvolver atividades que promovam a construção da lógica do sistema numérico e o conceito de número.

Para ambos, tanto a lecto-escrita quanto para as noções iniciais de matemática, esse trabalho descreve uma prática psicopedagógica na qual os dados da avaliação psicopedagógica - baseada na filação entre competências e dificuldades - foi seu o fundamento, como defendido por Fávero (2005). 


\section{III/ Método de Intervenção.}

\section{1/ Sujeito.}

Esse trabalho foi desenvolvido com um aluno do sexo masculino do $2^{\circ}$ ano do Ensino Fundamental de uma escola da Rede Pública do Distrito Federal, situada no Plano Piloto.

Daqui para frente chamaremos esse aluno de A., que tinha completado sete anos cerca de um mês antes de iniciarmos esse trabalho e não tinha, na sua história de escolaridade, nenhuma repetência.

Segundo a mãe de A. a sua professora do $1^{\circ}$ ano havia feito queixa sobre o seu rendimento escolar e no teste da psicogênese, obrigatório nas escolas do Governo do Distrito Federal, A. tinha obtido uma classificação abaixo do esperado para sua idade, ou seja, pré-silábica. Nada foi relatado sobre sua aprendizagem na iniciação a matemática.

Ao desenvolvermos esse trabalho, no início do segundo semestre, do corrente ano, a professora de A. se queixava de que "ele não acompanhava o ritmo da turma".

Foram com esses dados iniciais que iniciamos nosso procedimento psicopedagógico.

\section{2/ Procedimento Adotado}

Nosso procedimento psicopedagógico descrito em detalhes a partir do item IV, fundamentou-se na perspectiva de Fávero (2005) que defende a articulação entre dificuldades e competências de modo que, inicialmente procedemos a uma avaliação psicopedagógica focada nessa articulação e cujos dados fundamentaram a nossa prática 
de intervenção com A. Como podemos ver a descrição que se segue, cada sessão é relacionada à outra, de modo que os dados obtidos da análise da outra uma fundamenta a definição de objetivos e as atividades propostas.

IV/ A intervenção psicopedagógica: Tirando o foco das dificuldades para enxergar as competências.

\section{1/ Avaliação Psicopedagógica}

Foram realizadas cinco sessões de avaliação psicopedagógica sempre procurando focar as relações entre competências e dificuldades.

\section{- Sessão de avaliação psicopedagógica 1}

\section{-objetivo:}

Investigar a natureza das dificuldades e competências de A. nas atividades relacionadas a leitura: compreensão e interpretação de texto, com a utilização de uma história escrita e já utilizada em sua sala de aula.

\section{-procedimento e material utilizado:}

O texto escolhido está incluso no livro didático adotado pela escola de A. Tratava-se de um texto curto com apenas onze linhas. Sentados em uma mesa lado a lado, apresentamos a A. o referido texto, perguntando-lhe se ele se lembrava do mesmo. A resposta foi positiva e então procuramos explorar a figura que ilustrava o texto 
(uma minhoca sendo mantida por cada uma de suas extremidades por um passarinho). A. descreveu a figura com detalhes.

Iniciamos a leitura do texto tendo o nosso dedo indicador para acompanhar a sequência da leitura. A. imediatamente começou a ler o texto conosco.

Durante a leitura foram feitas diversas perguntas sobre o texto buscando investigar a compreensão de A., que respondeu a todas elas adequadamente.

\section{-resultados e discussão:}

A. leu o texto conosco e respondeu a todas as questões de compreensão do mesmo. Em contra-ponto, apresentou dificuldade na leitura de algumas palavras, tais como, aquelas cuja grafia possui nh, lh, ou seja, todas aquelas que fugiam da regra de sequência consoante/vogal. Em alguns momentos se adiantou a nossa leitura lendo sozinho a palavra. Porém isso só aconteceu com palavras e não com frases.

A dificuldade de A. frente às referidas palavras desaparecia quando ouvia nossa leitura de modo que se a mesma palavra voltasse a aparecer no texto A. a lia corretamente.

Quando questionado sobre qual era o sentido em que aparecia a palavras homônimas homógrafas A. soube responder qual era o sentido que a palavra tinha no texto.

No momento em que realizou o desenho da história ele pegou a folha e iniciou pela parte inferior da mesma, desenhando uma minhoca e utilizou seis cores diferentes para colori-la. Pode-se pensar que o fato de ter utilizado tantas cores para representar a minhoca, sugere que ele não sabia o era uma minhoca. 
A. demonstrou boa compreensão do texto e fluência verbal regular para uma criança que ainda não está com a alfabetização totalmente concluída.

- Sessão de avaliação psicopedagógica 2

\section{- objetivo:}

Investigar a natureza das dificuldades e competências de compreensão textual frente a uma história narrada.

\section{- procedimento e material utilizado:}

Convidamos A. a ouvir uma história conosco e em seguida propusemos: 1. Perguntas sobre a mesma, todas relacionadas a sua compreensão textual; 2. Que contasse a história com suas palavras.

Utilizamos projetor de som no qual a narração da história do Macaco e da velha (Coleção Disquinho: O macaco e velha. São Paulo:1961. Gravadora: Continental). A história tinha o total de 11 minutos e 29 segundos de duração. Entregamos uma folha sulfite branca de tamanho A4 para que A. realizasse um desenho.

\section{- resultados obtidos e discussão:}

Primeiramente, perguntamos A. se ele conhecia a história e ele respondeu que não. Perguntamos o que ele havia compreendido da história e, nesse momento, A. se referiu a poucos trechos da história e se confundiu em relação aos personagens e suas ações.

Questionamos sobre quem eram os personagens da história e ele incluiu o narrador da história como um dos participantes dela. A 
história era toda contada na terceira pessoa, o que excluía o narrador de participação nos eventos narrados. No primeiro momento da avaliação ele incluía o narrador nas ações realizadas pelo macaco e pela velha. Perguntamos quem era a velha Firinfifelha, personagem principal da história, ele não soube responder.

Solicitamos que ele desenhasse os personagens da história ouvida. A. desenhou três figuras: a velha, o macaco e um homem.

Frente aos dados obtidos, decidimos realizar uma nova sessão com o mesmo objetivo.

\section{- Sessão de avaliação psicopedagógica 3}

\section{-objetivo:}

Investigar a natureza das dificuldades e competências de compreensão textual frente a uma história narrada.

\section{- procedimento e material utilizado:}

Nessa sessão foi utilizamos um projetor de som onde a narração da história da Galinha Ruiva (Coleção Disquinho: A galinha ruiva. São Paulo: 2007.Gravadora: Warner Music) foi reproduzida. Dessa vez a história tinha um total de quatro minutos e vinte e nove segundos.

Ouvimos a história junto com A. Ao final, perguntamos a ele o que havia ocorrido na mesma. 


\section{-resultados obtidos e discussão:}

A. contou a história com suas palavras, dizendo seu título corretamente. Demonstrando compreensão quanto à sequência dos fatos relatados na história e terminou por anunciar espontaneamente qual era a moral da história.

No desenhou registrou o título da história, separando apenas a letra “ $A$ ” do restante das palavras. Colocou as palavras galinha e ruiva emendadas umas nas outras. A palavra galinha foi registrada com "nli" e ruiva foi registrada "ruva”. Com esse título supõe-se que ele está na hipótese silábica-alfabética dos níveis de alfabetização elucidados por Teberosky (1990).

O desenho foi feito todo na parte inferior da folha. Ele desenhou uma galinha amarela, e dois pintinhos, uma máquina de fazer pão e uma casa colorida. Dessa vez, ele não desenhou o sol e na parte superior colocou apenas o título da história.

O resultado alcançado com esta sessão evidencia que na sessão 3 a história escolhida era inadequadamente extensa e o local na qual desenvolvemos a atividade não era apropriado devido ao barulho.

\section{Sessão de avaliação psicopedagógica 4}

\section{- objetivo:}

Investigar as competências e dificuldades de A. em relacionar sons de letras e sua escrita.

\section{- procedimento e material utilizado:}

A. foi convidado a ouvir a música juntamente conosco e em seguida: 1. Solicitamos que ele acompanhasse a leitura da letra da música e colocasse o dedo indicador abaixo da palavra cantada; 2. 
Cantamos a música junto com A.; 3. Entregamos uma letra da música faltando algumas palavras e A. completou com as palavras que faltavam.

\section{-resultados obtidos e discussão:}

A. completou todas as palavras que estavam faltando na letra da música. Algumas palavras foram escritas com omissão de letras e troca de fonemas.

Utilizou-se de letra cursiva para escrever todas as palavras que faltavam. Além de fazer correspondência entre letra e som de palavras regulares: casa, rede e pipi. Já nas palavra com sílaba complexa, com dígrafo, A. utilizou a letra correspondente ao som da palavra. Escreveu chão com $x$.

Nas palavras parede e zero, trocou o r por 1. Escreveu "palede" e "zelo".

Na realização do desenho da letra da música, desenhou um balão de pensamento com um pinico dentro. Perguntamos a A. o que significava o desenho e ele nos respondeu que o homem estava pensando no pinico, já que a música falava que a casa não tinha pinico. Ele utilizou um lápis de cor gelo, bem claro para desenhar a casa.

Nessa sessão A. demonstrou facilidade em escrever palavras com escrita regular e criatividade em representar a música. Ficou evidente que A. ainda não está com sua alfabetização concluída, pois encontrou dificuldade em escrever o palavras com escritas irregulares. 


\section{- Sessão de avaliação psicopedagógica 5}

\section{-objetivo:}

Investigar quais são as competências e dificuldades de A. nas atividades relacionadas a matemática: correspondência entre número e quantidade, adição, sistema de medida de tempo e resolução de problemas.

\section{- procedimento e material utilizado:}

$\mathrm{Na}$ primeira atividade dessa sessão, entregamos a A. um calendário e um problema de adição que envolvia a utilização do sistema de medida de tempo. Já na segunda parte da sessão, entregamos a A. dois dados e sugerimos que fizéssemos um jogo em que ganharia quem marcasse mais pontos ao final de todas as partidas. Com esse procedimento buscamos avaliar qual era o conceito de número formado por A., bem como se conhecia os princípios de adição e subtração de quantidades.

Iniciamos a primeira parte da sessão com a leitura do problema juntamente com A. e depois deixamos que A. encontrasse qual seria a melhor estratégia responder o problema. Incentivamos A. a utilizar o calendário e os dedos para encontrar a resposta.

No segundo momento, propusemos um jogo onde A. deveria relacionar o número a quantidade. Entregamos dois dados a A. e solicitamos que ele os jogasse e fizesse a contagem de quantos pontos havia feito e logo em seguida também lançamos os dois dados novamente. A. teve que indicar quem havia feito mais pontos na partida. Fizemos um total de 24 lançamentos, 12 de A. e 12 nossos, e 
A. marcava o total de pontos de todas as partidas. No final, realizamos a contagem geral dos pontos.

\section{- resultados obtidos e discussão:}

Lemos o enunciado do problema juntamente com A. Ele não respondeu a pergunta do problema e então repetimos a leitura por mais três vezes e ele continuou sem responder.

Iniciamos, então, perguntas sobre o calendário. Respondeu corretamente qual era o dia e o mês. Procedemos questionando qual era o primeiro dia de aula da semana e ele disse que era terça-feira. Perguntamos a A. se ele havia comparecido a aula no dia anterior e ele respondeu que sim. Após essa pergunta ele disse que a semana de aula iniciava na segunda-feira e não na terça-feira corrigindo assim sua resposta. Questionamos quantos e quais eram os dias da semana. Ele corretamente quais eram os dias da semana e disse que totalizavam 10 dias. Solicitamos que ele utilizasse os dedos da mão para contar quantos eram os dias da semana e ele respondeu que eram sete.

Fizemos a leitura do problema novamente a A. e ele respondeu que iria necessitar de $\mathrm{R} \$ 1,50$ para comprar as cartinhas que custavam $\mathrm{R} \$ 1,00$ para cada dia de aula da semana. Informamos a A. que a resposta estava errada pois com $\mathrm{R} \$ 1,50$ ele só poderia comprar a revistinha uma vez na semana de aula. Pedimos que ele contasse nos dedos e ele respondeu corretamente “ $R \$ 5,00$ ”.

Ao final dessa primeira atividade ele registrou a resposta na folha desenhando uma nota de $\mathrm{R} \$ 5,00$ e colocou a letra inicial dos dias de semana em que tem aula.

Já na segunda atividade propusemos que A. lançasse dois dados e fizesse a contagem dos pontos do dados. Em seguida, nós 
lançávamos os dois dados, e posteriormente, ele espontaneamente ele fazia a contagem dos nossos pontos e registrava os dois numa folha. Prosseguimos com esses lançamentos por vinte e quatro vezes, doze vezes por A. e doze vezes por nós. Durante essa atividade fizemos algumas perguntas e A. as respondeu corretamente. Perguntamos quem havia feito mais pontos em cada lançamento e quantos pontos deveria tirar nós a mais para que fizéssemos mais pontos que ele e, por fim, somamos todos os pontos juntamente com A.

Concluímos que A. realiza contagem oral da e relaciona o número a quantidade, destarte precisas ser familiarizado com o nosso sistema de medida de tempo e sistema monetário.

\subsection{1/ Discussão geral da avaliação psicopedagógica.}

Foram realizadas cinco sessões de avaliação psicopedagógica conforme descritas anteriormente. Todas tiveram por objetivo avaliar quais eram as competências e as dificuldades de A. em relação a aspectos importantes para seu desenvolvimento em atividades escolares de crianças de mesma idade, tais como: a leitura, a escrita e construção da noção de número.

Acreditamos que a avaliação psicopedagógica é imprescindível para fundamentar uma intervenção que valorize as competências e, a partir delas, criar situações propícias para o desenvolvimento de outras. Sendo assim, buscamos avaliar como A. desenvolvia as atividades que lhe eram propostas.

Os dados da nossa avaliação evidenciaram - ao contrário da visão da sua professora - que A apresentava competências de compreensão textual, diante de textos próprios à sua faixa etária e à sua escolaridade, assim como diante de textos de letra de músicas e diante de gravações de histórias curtas narradas. 
Sua dificuldade se restringe, o que é comum para quem se encontra em processo de alfabetização, à leitura e escrita de palavras que apresentam estruturas irregulares, isto é, fora do padrão da relação consoante-vogal.

Durante o desenvolvimento das atividades de matemática A. revelou conhecer a ordem dos números e diferenciar números de maior e de menor quantidade, isto é, estabeleceu a relação entre número e quantidade. Deste modo, podemos dizer que A. apresentou a noção de número. Suas dificuldades se relacionaram às que envolviam nosso sistema de medida de tempo.

Na última sessão, ficou evidente que A. precisa de um ambiente que tenha características diferentes das usuais de sua sala de aula, pois quando as atividades propostas eram semelhantes àquelas que sua professora propunha em sala de aula ou quando conduzíamos nossas perguntas tal como é a prática de sua professora ele apresentava dificuldades em desenvolver o proposto.

Assim, por exemplo, quando lhe propusemos uma situação problema, no primeiro momento, sua reação foi permanecer calado. Quando nós mesmas, durante este estágio, desenvolvemos a competência de conduzir a atividade proposta de tal modo que o conduzisse a interagir com o proposto, segundo nossa mediação, o que se constituía em um procedimento completamente diferenciado da sua vivência em sala de aula. A. apresentou competências e desenvolveu outras. Assim, na segunda atividade proposta nessa sessão A. teve agilidade para desenvolve-la, tratou-se de uma atividade diferente das feitas em sala de aula.

Acreditamos que o ambiente de sala de aula pode ser ameaçador para A. Voltaremos a este ponto nas nossas discussões gerais. 
Diante do exposto, concluímos que as sessões de intervenção deveriam focar:

1 - na leitura e compreensão de textos com palavras irregulares e focar na conceito de número com ênfase na relação número/quantidade através de situações problema envolvendo as diferentes medidas; e

2- na intervenção numa relação diferenciada com A. , isto é diferenciada daquela que caracterizava a interação da sua professora com ele. Isso significava discutir soluções e procurar seu ponto de vista sobre estas e evitar perguntas padronizadas de sala de aula como por exemplo: “Você tem certeza? Presta atenção? É isso mesmo?” e etc.

\section{2/ As Sessões de Intervenção.}

\section{- Sessão de intervenção psicopedagógica 1}

\section{-objetivo:}

Desenvolver atividades que foquem a escrita de palavras irregulares.

\section{- procedimento e material utilizado:}

Apresentamos a A. um folheto de super-mercado e pedimos que ele observasse todos os produtos que estavam sendo anunciados no folheto. Em seguida, perguntamos a A. se havia algo no folheto que ele gostaria de ter.

Entregamos uma folha branca de tamanho A3, uma tesoura, uma cola e um pincel de cor vermelha para A. Solicitamos que ele recortasse os produtos que gostaria de ter. Por fim, sugerimos que A. 
juntamente conosco colocasse o nome de cada um desses produtos ao lado da figura recortada e colada na folha A3.

\section{- resultados obtidos e discussão:}

A. folheou todo o folheto do super-mercado. Quando solicitado a recortar os produtos ele escolheu cinco produtos. O primeiro produto escolhido foi uma bicicleta, o segundo foi um pneu, o terceiro um DVD, o quarto uma barraca e o último uma pá de jardinagem.

Indagamos a $A$. quais eram os produtos que ele havia escolhido e ele respondeu: "bicicleta, pneu, carro, barraca e pazinha”. A palavra carro fazia referência a figura de um DVD que tinha a figura de um carro na capa e a pazinha fazia referência ao tamanho da pá, que era pequena.

A primeira palavra escolhida por A. foi a palavra "carro", que ele escreveu apenas com um "r". Perguntamos se aquilo era caro ou carro. Percebeu que o som do r deveria ser escrito com duplo r já que o r estava no meio da palavra. "A língua não treme então são dois", disse A. ao corrigir a palavra. Perguntamos quais eram as outras palavras que ele conhecia com duplo $r$ e ele respondeu: "marreco, morro e murro".

A segunda palavra escrita por A. foi pneu. Ele iniciou escrevendo a letra "p" e, posteriormente, solicitou nossa ajuda para escrever a segunda letra. Depois reconheceu o valor sonoro da letra $p$ como se fosse acompanhado por uma vogal, formando uma sílaba regular, composta de consoante e vogal. Achou que era acompanhado por uma vogal. Explicamos que era uma palavra irregular e ele resolveu copiar diretamente do panfleto do super-mercado. 
A terceira palavra escrita foi barraca. A.escreveu a palavra corretamente sem necessitar de auxílio. Ele pronunciava a sílaba em voz alta e fazia o registro na folha.

A quarta palavra foi bicicleta. Ele encontrou dificuldade em escrever a segunda sílaba e perguntou: "Como é que faz o cle?". Solicitamos que ele procurasse no panfleto. Novamente copiou do folheto. Perguntamos lhe se conhecia outras palavras que poderiam ser escritas dessa mesma maneira e respondeu que não. Listamos a A. algumas palavras em que havia a ocorrência de "cl".

A última palavra escrita por A. foi pazinha. Ele procurou no panfleto e encontrou a palavra pá. Ele percebeu que a palavra não estava escrita no diminutivo e nós escrevemos a palavra no diminutivo.

A. ainda recortou a figura de um brinquedo, mas não registrou o nome da figura na folha como fez com as palavras anteriores.

\section{- Sessão de intervenção psicopedagógica 2}

\section{-objetivo:}

Desenvolver atividades que foquem o conceito de número através de uma situação problema envolvendo sistemas de medida de tempo e monetário.

\section{- procedimento e material utilizado:}

Selecionamos um produto anunciado no folheto de mercado utilizado por A. na primeira sessão. Propusemos que ele solucionasse a seguinte situação problema: "Você viu no folheto do supermercado um produto que gostaria de comprar. Você recebe uma mesada de $R \$$ 
15,00 por mês. Se decidir não gastar nada da sua mesada. Quanto tempo você precisará para comprar o produto que você gostou?”. Visando, assim, trabalhar o conceito de número através de diferentes sistemas de medidas. A situação problema estava digitada numa folha branca de tamanho A4 entregamos a um calendário e cédulas de diferentes valores para que que A. pudesse resolver o problema proposto foi lido juntamente conosco.

\section{- resultados obtidos e discussão:}

Iniciou a atividade contando as cédulas e juntou o valor suficiente para comprar o produto. Propusemos que A. separasse o valor que ele receberia por mês contasse quantos meses seriam suficientes para comprar o produto. Ele observou que apenas dois meses também não seriam suficientes e juntando três meses o valor passaria do necessário. Concluiu que sobraria um troco de R \$10,00.

Solicitamos que A. registrasse na folha o cálculo que ele havia feito e respondesse a pergunta feita no final do problema. Ele não apresentou dificuldade em registrar os cálculos. Iniciou colando as parcelas dos dois primeiros meses e fez uma segunda conta para calcular o valor de mais um mês que seria necessário para comprar o produto. Colocou ao lado de cada uma das parcelas o mês em que seria adquirido tal valor: no primeiro registrou o número 1 ; no segundo mês o número 2 e no terceiro mês o número 3 . Ele escreveu na parte inferior da folha: " 3 meses".

\section{- Sessão de intervenção psicopedagógica 3}

\section{- objetivo:}

Mediar a interação de A. com nosso sistema monetário e familiariza-lo a escrita de palavras com escrita irregular. 


\section{- procedimento e material utilizado:}

Sugerimos que A. escolhesse no panfleto de mercado um lanche para levar a escola com valor de $\mathrm{R} \$ 5,00$. Assim que escolhido entregamos a A. uma folha branca onde ele deveria escrever o nome do produto/marca produto escolhido e depois realizasse a subtração do valor de $\mathrm{R} \$ 5,00$ com o valor da soma dos produtos por ele escolhidos.

Depois entregamos a A. uma caixa onde haviam notas e moedas com diversos valores e solicitamos que representasse o valor de $R \$$ 5,00 com notas ou moedas diferentes do que a nota de R \$ 5,00.

\section{- resultados obtidos e discussão:}

Nessa sessão A. utilizou o folheto para escrever o nome de todos os três produtos escolhidos por ele: "toddynho, biscoito $e$ pipoca”. Cada um desses produtos estavam custando o valor de R $\$$ 1,00 , vez que desconsideramos a parte decimal do valor do produto. Decidimos desconsiderar os centavos dos produtos porque A. ainda não havia trabalhado esse conceito em sala de aula.

Ele fez a subtração sem nenhuma dificuldade e registro no seu caderno.

Já no segundo momento ele iniciou dispondo cinco notas de R 1,00 em cima da mesa em que trabalhávamos. Perguntamos a A. se existiam outras maneiras de se obter $\mathrm{R} \$ 5,00$ e ele retirou cinco moedas de $\mathrm{R} \$ 1,00$ e as colocou em cima da mesa. Ele disse que também poderia ser feito com duas notas de $R \$ 2,00$ e uma nota de $R \$$ 1,00. Solicitamos que ele fizesse o registro dessas cédulas na folha. A. não teve dificuldade para realizar essa tarefa. 


\section{- Sessão de intervenção psicopedagógica 4}

Estimular A. a reconhecer o valor e sequência dos números naturais.

\section{- procedimento e material utilizado:}

Persistimos na utilização do folheto de super-mercado para realizar essa sessão. Demandamos A. que escolhesse vários produtos no folheto e depois os colasse numa folha um atrás do outro de maneira crescente.

\section{- resultados obtidos e discussão}

A. escolheu seis produtos nos folhetos. Recortou cada um e em seguida os colocou lado a lado. Colocou três produtos de $\mathrm{R} \$ 1,00$, depois dois de $R \$ 2,00$ e por fim o que custava $R \$ 3,00$. Questionamos a A. porque ele havia colocado o primeiro produto na primeira posição e o segundo após, afinal eles custavam a mesma quantia em reais. Ele disse que não sabia onde poderia colocar já que o valor deles era o mesmo.

Sugerimos a A. que fizesse uma linha reta numa folha A4 e que colocasse os produtos escolhidos de acordo com o valor. Ele optou por colocar os produtos de mesmo valor um abaixo do outro. Assim, na posição um haviam três produtos, na posição dois haviam dois produtos e na posição três um produto.

Completamos a sessão entregando a A. três produtos selecionados por nós. Um tinha o valor de R \$ 0,99, um de R \$2,50 e um de R \$ 13,00. Solicitamos que ele colocasse esses três produtos na sequência e ele não encontrou nenhum impedimento para realizar essa tarefa. 


\section{- Sessão de intervenção psicopedagógica 5}

\section{-objetivo:}

Ampliar o conceito de número através da utilização dos sistemas de medida de tempo e monetário.

\section{-procedimento e material utilizado:}

Nessa sessão buscamos trabalhar com o nosso sistema de medida de tempo, através da proposta de uma situação problema que necessitava do uso do calendário por A. Iniciamos entregando o material produzido por ele na quarta sessão de intervenção e lhe comunicado oralmente a situação problema. A problemática foi feita baseada nas escolhas que A. havia feito na sessão 3. A situação: Se você resolvesse comprar esse mesmo lanche todos os dias até o término das aulas, quanto gastaria?

Disponibizamos para A. uma folha em branco e um calendário escolar produzido pela Secretária de Educação no qual direcionamos nossas perguntas.

A tarefa consistia em responder oralmente várias situações problemas que ora envolviam o sistema de medida de tempo ora o nosso sistema de medida monetário, ou ambos concomitantemente.

Depois que respondesse oralmente A. deveria registrar no papel branco as respostas das perguntas elaboradas por nós.

\section{- resultados obtidos na sessão:}

Assim que solicitamos que relembrasse a sessão ele identificou quais eram os produtos por ele escolhido na sessão três. Iniciamos 
com uma série de perguntas: 1. Quais eram os dias da semana? Quais eram os dias que ele vinha para escola na semana?; 3. Quantos eram os dias que ele vinha para escola e quantos eram o dias que ele não vinha para escola?.

Ele não respondeu quantos eram os dias da semana em que não havia aula. Disse que vinha para a escola todos os dias da semana. Acreditamos que ele respondeu baseado apenas nos dias úteis da semana. Explicamos a A. que estávamos fazendo referência a semana completa que iniciava no domingo e terminava no sábado. Após essa explicação ele respondeu corretamente essa questão.

Ele encontrou no calendário a data da intervenção e contou quantos eram os dias da semana que ele teria aulas. Inclusive apontou com o dedo indicador quais eram os dias em que ocorreria aula na semana.

Identificamos algumas das legendas que apareciam no calendário juntamente com ele. Fizemos outras perguntas: 1. Que dia acabavam as aulas?; 2. Qual era o dia em que ele entraria de férias?; 3. Quantos eram os dias que faltavam para acabar o ano?; 5. Quantos eram os feriados até o fim do ano?; 6. Quanto dias de aula faltam para acabar as aulas?; 7. Se fossemos contar em semanas, quantas faltavam para acabar o ano?

Dessa vez A. utilizou um lápis para apontar os dias do calendário e realizou as contas oralmente. Respondeu as duas primeiras perguntas sem nenhuma dificuldade. Na terceira errou a data. Informamos a $A$. que a pergunta se referia a último dia do ano de 2011. Prosseguiu a intervenção contando quantos seriam os dias para acabar o ano e acertou a resposta. Identificou quais eram os dias de feriado. Não respondeu corretamente o número de semanas que faltavam para acabar o ano. Solicitamos que ele agrupasse os dias em sete dias: iniciando sempre do domingo e terminando no sábado que 
apareciam em cada linha do calendário e realizamos a contagem do número de semanas que faltavam para acabar o ano juntamente com $\mathrm{A}$.

Por fim, pedimos que A. anotasse numa folha as respostas das perguntas e relemos para A. a situação problema que deveríamos resolver. Ele colocou em sequência todos os dias até acabar as aulas e abaixo de cada dia ele anotou o valor de $\mathrm{R} \$ 3,00$. A. solicitou nossa ajuda para somar todos os valores.

\section{- Sessão de intervenção psicopedagógica 6}

Avaliar o processo de intervenção psicopedagógica desenvolvida $\operatorname{com} \mathrm{A}$.

\section{- procedimentos e materiais utilizados}

Apresentamos a uma situação problema que envolvia a utilização de sistemas de medidas de tempo e monetária. Entregamos várias notas de dinheiro, um calendário e uma folha com a seguinte situação problema: "Você viu no supermercado uma bicicleta, do modelo que você queria na promoção por $\mathrm{R} \$ 120,00$. Essa promoção terá a duração de 15 dias. Você melhorou sua mesada e passou a receber uma mesada de $\mathrm{R} \$ 10,00$ por dia, ou seja, $\mathrm{R} \$ 310,00$ ou $\mathrm{R} \$$ 300,00 dependendo do mês, de seus pais. Então resolve economizar da seguinte maneira: $1^{\circ}$ dia, $R \$ 10,00 ; 2^{\circ}$ dia, $R \$ 10,00 ; 3^{\circ}$ dia, $R \$ 10,00$; $4^{\circ}$ dia $\mathrm{R} \$ 10,00$ e assim por diante. Economizando desse modo, de quantos dias você precisará para ter dinheiro suficiente para comprar a bicicleta?". 


\section{- resultados obtidos com a sessão}

Ele necessitou de nossa ajuda para ler a situação problema. A. posicionou o seu dedo indicador abaixo das palavras pronunciadas. Novamente ele leu vários trechos antes de nós. Ele releu a situação problema duas vezes sem o nosso auxílio.

Iniciou a resolução da situação problema contando os dedos por várias vezes seguida. Ele pegou dez notas de $\mathrm{R} \$ 10,00$ nas mãos e as contou e disse que só faltava dois dias para comprar a bicicleta. Ele respondeu a situação problema oralmente e não fez o registro da resposta na folha. Apenas disse: "Vou precisar juntar dinheiro durante doze dias para comprar a bicicleta”.

\section{V/ Discussão geral dos resultados da intervenção psicopedagógica.}

Foram desenvolvidas 6 sessões de intervenção, sendo a última elaborada para avaliar o processo de intervenção aplica do em A.. As sessões foram descritas em termos de objetivos; procedimentos e materiais utilizados; e resultados obtidos. Todas as sessões foram registradas em áudio, transcritas e avaliadas em termos de competências e dificuldades. Cada sessão era de acordo com a sessão anterior, e a análise fornecia os dados para a construção de uma nova intervenção. As sessões será descritas em sequência.

$\mathrm{Na} 1^{\text {a }}$ sessão utilizamos folhetos de mercado com ofertas. Sugerimos que ele escolhesse no folheto alguns produtos que gostaria de comprar. Ele deveria recortar estes produtos e colocar o nome de cada um deles próximo a figura. O objetivo era trabalhar leitura e escrita de palavras irregulares. Ele apresentou dificuldade em 
escrever em escrever quatro das cinco palavras. A. ainda escolheu um sexto produto e não quis escrever o nome.

A $2^{a}$ sessão, foi organizada para familiarizar A. com a palavra por ele escolhida na primeira sessão e não registrada. O foco dessa sessão era trabalhar o conceito de número através da resolução de uma situação problema que envolvia o sistema monetário e sistema de medida de tempo. A. utilizou o calendário e notas e moedas de dinheiro para auxiliar na adição e notação do resultado.

A $3^{a}$ sessão centrou-se na interação de A. com o nosso sistema de medidas, ele foi incentivado a trabalhar com diferentes notas de dinheiro e a realizar contagem do dinheiro, a partir da retirada de determinados valores. Ainda, solicitamos que A. anotasse o nome da cada um dos produtos e assim treinasse a escrita dessas palavras. Tomamos o cuidado de retirar os centavos dos valores que apareciam nos produtos, vez que A. ainda não havia aprendido a realizar adição e subtração com valores não inteiros nessa idade. Ele não apresentou dificuldade em adicionar e subtrair valores de números inteiros.

$\mathrm{Na}$ quarta sessão trabalhamos a sequência de números naturais e também com números que tinham valores não inteiros na sua formação. Novamente tomamos o cuidado de retirar a parte parcial (centavos) da maioria dos produtos que tivessem centavos, apenas deixamos os produtos que tinham cinquenta centavos na parte dos centavos e também um produto que custava 0,99. Ele foi incentivado ir e vir na contagem e operações com as notas. Ele construiu uma linha reta onde deveria colocar os produtos em sequência do maior para o menor. No início A. teve dificuldade em classificar os produtos que tinham o mesmo valor, pois colocou um após o outro, o que implicou em erro, pois cada produto deveria ficar na mesma posição do produto que tivesse valor semelhante. Após o esclarecimento, ele acertou a posição de todos os produtos e inclusive dos dois que ele 
não havia escolhido e que entregamos para que ele classificasse. Acertou a posição do refrigerante que custava $\mathrm{R} \$ 0,99$ e do biscoito que custava $\mathrm{R} \$ 2,50$.

A $5^{\text {a }}$ sessão foi feita organizada com os produtos que A. havia feito na $3^{\text {a }}$ sessão. Criamos uma situação problema que envolvia o sistema de medida de tempo e sistema monetário. O foco era desenvolver a apropriação do sistema de medida e de tempo através da utilização do calendário. A. teve dificuldade com o sistema de medida de tempo em relação a contagem do tempo em semanas.

Seguimos nosso trabalho buscando avaliar o desempenho de A. depois que foram aplicadas as 5 sessões de intervenção. Apresentamos a A. a seguinte situação problema: "Você viu no supermercado uma bicicleta no modelo que você queria na promoção por R\$120,00. Essa promoção terá a duração de 15 dias. Você melhorou sua mesada e passou recebe uma mesada de R \$10,00 por dia, ou seja, R\$310,00 ou $\mathrm{R} \$ 300,00$ dependendo do mês de seus pais. Então resolve economizar da seguinte maneira: $1^{\circ}$ dia, $\mathrm{R} \$ 10,00 ; 2^{\circ}$ dia, $\mathrm{R} \$ 10,00 ; 3^{\circ}$ dia, $\mathrm{R} \$$ 10,$00 ; 4^{\circ}$ dia $\mathrm{R} \$ 10,00$ e assim por diante. Economizando desse modo, de quantos dias você precisará para ter dinheiro suficiente para comprar a bicicleta?". Entregamos a uma folha em branco, um calendário e diversas notas de dinheiro. Lemos o problema juntamente com A.. Ele posicionou seu dedo indicador abaixo das palavras pronunciadas. Durante a leitura ele leu antes de nós por várias vezes o que evidenciou uma melhora significativa de sua leitura. No momento em que foi realizado a situação ficamos em silêncio e solicitamos que ele resolvesse sem o nosso auxílio. Ele leu o problema por duas vezes e depois começou a contar nos dedos. Quando chegou no décimo dia anotou na folha o número dez e continuou o contar mais dois dedos na mão e chegou ao décimo 
segundo dia. Ele apenas anotou o 12 na folha e respondeu oralmente: "Vou precisar ficar sem gastar doze dias".

A sessões de intervenção se mostraram eficazes para atingir um focos dessa intervenção, que foi: a leitura e compreensão de textos com palavras irregulares e focar na conceito de número com ênfase na relação número/quantidade através de situações problema envolvendo as diferentes medidas. A utilização de um material presente no cotiano de A. foi importante para que ele se familiarizasse com as palavras e pudesse tomar consciência de suas ortografias.

O segundo foco da intervenção foi: a construção de uma relação diferenciada com A., isto é diferenciada daquela que caracterizava a interação da sua professora com ele. Isso significava discutir soluções e procurar seu ponto de vista sobre estas e evitar perguntas padronizadas de sala de aula como por exemplo: "Você tem certeza? Presta atenção? É isso mesmo?" e etc. Sem dúvida essa foi um dos aspectos mais difíceis da nossa intervenção, pois dependeu da mudança de atitude da professora, aqui como autora, em relação A.. Nesse ponto a orientadora contribui para que ocorresse a tomada de consciência da autora em relação ao ambiente de aprendizagem. A cada encontro novos pontos eram questionados e autora podia observar suas atitudes em relação ao sujeito da pesquisa. A estratégia foi fundamental para que a relação entre A. e a professora fosse bilateral e surgisse um ambiente de aprendizagem construtor do conhecimento.

Concluímos que a aplicação dessa intervenção foi satisfatória tanto para A. quanto para a autora. Ambos conseguiram criar uma nova relação com o conhecimento, o objeto do conhecimento e com os sujeitos envolvidos no conhecimento. Essa mudança foi perceptível das sessões de avaliação até as de intervenção. 


\section{VI/ Consideração finais.}

A possibilidade de entrar em contato com um estudo de caso, contribui efetivamente para o nosso futuro profissional em Psicopedagogia. A possibilidade de utilizar nossos conhecimentos sob a orientação de um de nossos professores nos ajuda a perceber na prática tudo o que estudamos nessa pós-graduação. Sem dúvida, esse estágio abre possibilidades de agirmos como psicopedagogas e atribuir sentido para todo o nosso curso.

A proposta de intervenção desse estágio era baseado na articulação entre competências e dificuldades na prática psicopedagógica buscando contribuir para que A. realize sua aprender de modo mais satisfatório.

A articulação entre as competências e dificuldades de A. em relação a lecto-escrita e a matemática foi fundamental para a o sucesso dessa intervenção. A utilização de material escrito presente no seu cotidiano e instrumentos de medidas, também utilizados em seu cotidiano foi eficaz para o sucesso da nossa intervenção.

O fato de A. sempre poder está em contato com o material escrito e lidar com situações problemas suscitadas a partir das escolhas dele contribuíram para que as situações problemas e prática de leitura escrita de palavras fossem mediadas a partir do interesse de A.. A escolha de situações problemas que envolviam a utilização de instrumentos de medida auxiliou a construção do conceito de número por A. Bem como, relacionar número a quantidade.

A mudança de comportamento da autora, que era sua professora, é notável em todo trabalho. Afinal, foram desenvolvidas durante esse trabalho novas competências tanto durante a prática quanto nos momentos de atendimentos feitos pela a orientadora com a autora. 
Acreditamos que articular as competências e as dificuldades garante identidade ao sujeito da pesquisa. Ele passa a ser percebido como um sujeito que constrói seu conhecimento, não apenas na prática escolar mais no seu dia a dia. Negar que ele aprenda fora da escola e negar sua identidade. Assim, não apenas ele constrói novas competências mas todos os envolvidos na relação de aprendizagem, seja ela na escola ou não.

\section{VII/ Referências Bibliográficas.}

BARRERA, Sylvia Domingos \& MALUF, Maria Regina. (2003). Consciência metalinguística e alfabetização: um estudo com crianças da primeira série do ensino fundamental. Psicologia: Reflexão e Crítica.Vol.16, n.3, pp. 491-502.

CAPOVILlA, Alessandra Gotuzo Seabra \& CAPOVILlA, Fernando César e SUITER, Ingrid. (2004). Processamento cognitivo em crianças com e sem dificuldades de leitura. Psicologia em estudo. Vol.9, n.3, pp. 449-458.

COLOMER \&Camps Anna. (Fátima Murad, trad.).(2002). Ensinar a ler, ensinar a compreender. Porto Alegre: Artmed.

CUNHA, Célio de \& FÁVERO, Maria Helena (org).(2009). Psicologia do conhecimento: o diálogo entre ciências e a cidadania. Brasília: Unesco, Instituto de Psicologia da Universidade de Brasília, Liber Livro Editora.

FÁVERO, Maria Helena.(2005) Psicologia e conhecimento: subsídios da psicologia do desenvolvimento para a análise de ensinar e aprender / Maria Helena Fávero - Brasília: Editora Universidade de Brasília. 
MARTINS, Maria Helena. O que é leitura. São Paulo: Brasiliense, 1994.

NOGUEIRA, Clélia Maria Ignatius. Educar em Revista, Curitiba, Brasil, n. Especial, p.109-124, 2011. Editora:UFPR.

NUNES, Terezinha e BRYANT, Peter. Crianças fazendo matemática. Porto Alegre: Artes Médicas, 1997.

OLIVEIRA, Vera B. e BOSSA, Nádia A (org), Avaliação Psicopedagógica da Criança de Zero a Seis Anos. 17. Ed., Petrópolis: Vozes, 2008.

TEBEROSKY, Ana. Psipedagogia da linguagemescrita, TEBEROSKY, Ana.Psicopedagogia da linguagemescrita .(Beatriz Cardoso,trad.). 2. ed. Editora da Unicamp, 1990. 